\title{
Mortality and Morbities of Severe Stroke in Limited Ressources Neurological Service
}

\author{
Komi Assogba ${ }^{1, ~ *}$, Kossivi Apetse ${ }^{1}$, Watouo Marlène Djobosse ${ }^{1}$, Lantam Sonhaye ${ }^{2}$, Nynèvi Anayo ${ }^{1}$, \\ Panabalo Waklatsi $^{1}$, Abdoulah Blakime ${ }^{1}$, Victor Kokou Adjenou ${ }^{2}$, Koffi Agnon Ayélola Balogou ${ }^{1}$ \\ ${ }^{1}$ Neurology Department, Campus University Teaching Hospital, University of Lomé, Lomé, Togo \\ ${ }^{2}$ Radiology and Medical Imagery Services, Campus University Teaching Hospital, University of Lomé, Lomé, Togo
}

Email address:

chocob400@gmail.com (K. Assogba), seraphinassogba $a$ hotmail.com (K. Assogba)

${ }^{*}$ Corresponding author

\section{To cite this article:}

Komi Assogba, Kossivi Apetse, Lantam Sonhaye, Watouo Marlène Djobosse, Nynèvi Anayo, Panabalo Waklatsi, Abdoulah Blakime, Victor Kokou Adjenou, Koffi Agnon Ayélola Balogou. Mortality and Morbities of Severe Stroke in Limited Ressources Neurological Service. Clinical Neurology and Neuroscience. Vol. 3, No. 2, 2019, pp. 50-57. doi: 10.11648/j.cnn.20190302.15

Received: February 22, 2019; Accepted: April 9, 2019; Published: June 29, 2019

\begin{abstract}
Introduction: Severe strokes have poor prognosis by their heavy motor and cognitive consequences. Objective: To describe the epidemiological, clinical and therapeutic aspects of these strokes. Material and Method: A retrospective and analytical study was conducted from January 2015 to December 2016 in the neurology department of our University Hospital. The diagnosis of severe stroke was based on clinical criteria (NIHSS score greater than 17, Glasgow score less than 9, and a WFNS stage greater than or equal to IV); and CT scan criteria (stroke location in the posterior fossa, carotid and Sylvian malignant infarction, cerebral hemorrhage with ventricular flood and mass effect). Results: We recorded 1964 strokes and 163 patients had severe stroke with a frequency of $8.3 \%$. Of the 163 severe strokes, ischemic were observed in $38.7 \%$ and hemorrhagic for $61.3 \%$. The average age was $55.8 \pm 12.8$. The motor deficit $(76.1 \%)$ and disturbances of consciousness $(62.6 \%)$ were the most admission signs. High blood pressure was the main risk factor $(64.8 \%)$ and the etiology of hemorrhage in $83.5 \%$. Atherosclerosis was the main etiology $(86.4 \%)$ of ischemia. The hemorrhagic lesions location was diencephalic $(67.7 \%)$ and brainstem $(21.7 \%)$. Overall mortality was $44.8 \%$, including $72.6 \%$ of early mortality due to haemorrhage. Predictive factors of mortality were the high NIHSS score, low Glasgow score, presence of ventricular flood, and high volume of hematoma. Conclusion: The high incidence of severe stroke and its early mortality rate demonstrate that many challenges remain to be done to improve the management of patients and avoid disabling sequelae.
\end{abstract}

Keywords: Epidemiology, Clinical, Severe Stroke, Treatment

\section{Introduction}

Stroke is a major health challenge, placing a substantial burden on health care systems. Each year 15 million people suffer a stroke worldwide, six millions die and another five millions experience long-term disabilities. The significant and complex physical, cognitive, and emotional deficits require continued lifelong follow up and support [1-3].

Intracerebral haemorrhages accountered for $35 \%$ and large vessels trunk infarction for $65 \%$ in the acute phase of stroke. These kind of severe strokes are caused malignant disease with $80 \%$ of death or disabled for life, mainly in tropical countries. The severe stroke is one that causes immediate heavy disabling sequelae and high mortality rate. There is clearly a need to understand how to reorganize stroke care systems and develop quality interventional local practices [4, 5]. In developed countries, the neurovascular units with an organized stroke pathway medical system save life and improve the vital and functional prognosis of patients $[6,7]$. Computed tomography (CT) scan and or MRI are the investigations of choice medical imagery tools for the initial assessement and rule out the diagnostics to establish the treatment in accordance with the guidelines used in neurovascular units. [8, 9] Recent studies have proven the safety and efficacy of endovascular therapy, surgical therapy and thrombolysis therapy for stroke attacks and help to 
reduce disabilities and patient inhospital lengh of stay [10, $11]$.

In developing countries, severe stroke management remains a great challenge. These difficulties are related to the insufficiency of the technical tools, the difficult access to medical imaging, and the delay of admission to specialized care units $[12,13]$. The neurological status at the initial presentation and the interval between onset and therapeutic intervention contributes to the prognosis [14-16]. The high rate of first and recurrence stroke is largely due to poor risk factor control, place increasing emphasis on the importance of developing, evaluating, and implementing preventive strategies [17-19].

The objective of this study was to determine the epidemiological and clinical features of severe stroke in limited resources setting.

\section{Material and Method}

\subsection{Study Framework}

This study was carried out in the neurology department of our tertiary teaching hospital. It hosts patients from all over the country, whose population was estimated to 6 million inhabitants in 2013. It has a capacity of 167 beds with various services including medical and surgical specialties. The neurology department has 37 beds, with a total of 850 hospitalizations per year, a consultation unit of 3600 patients per year, and a clinical neurophysiologic laboratory. The service drives the activities of care, research and teaching. Patients are most often referred directly despite the absence of an organized stroke pathway. Only CT scan is an emergency imaging available. Thrombolysis and endovascular cerebral therapy are not effective at this time.

\subsection{Method and Population of Study}

It was a retrospective, descriptive and analytical study carried out from January 2015 to December, 2016. The diagnosis of severe stroke was made on the basis of criteria associating clinical and radiological parameters. Severe stroke was defined as stroke with an NIHSS score greater than 17, Glasgow less than 8 and a WFNS stage greater than or equal to IV. The brain imaging must revealed hematoma in the posterior fossa, parenchymatous hemorrhage with ventricular flooding and commitment effect, meningeal hemorrhage classified at stage 3 and 4 according to Fisher's classification, and occlusion of large carotid arterial trunks or vertebral basilar artery. Patients excluded were those with subdural hematomas, cerebral venous thrombosis or incomplete files including patients who died before the brain scan.

All patients with severe stroke were systematically selected and reviewed to ensure eligibility. The selected files were analyzed per year. The re-reading of brain imaging was done both by a neurologist and a radiologist for the exact determination of infarcted arterial territory, the anatomical location and measurement of the hematoma and the visualization of other lesions.
Two groups of variables were studied, epidemiological and clinical. The epidemiological variables were composed of sociodemographic variables (age, sex, profession, marital status). Clinical and therapeutic variables were represented by antecedents and risk factors, inaugural symptoms, the NIHSS and Glasgow scores at the admission, brain imaging lesions, and etiologies. The therapy instituted and the evolution through the mode of exit was quoted in two items, return to home or deceaded.

For the NIHSS and Glasgow scores, stroke was considered to be very serious; those with an NIHSS score between 17 and 20 and / or a Glasgow score between 6 and 8, gravissim, those with an NIHSS score greater than 9 and / or a Glasgow score less than 6 .

For the cerebral imaging variables, it was noted in case of hematoma, a supra-tentorial localization, the extension in height (sub-cortical, bulbar, protuberant, and peduncular) and other lesions or complications (blood ventricular contamination, axial involvement, and hydrocephalus). The dimension heamatomas lesions were determined by a radiologist in two parameters including volume and maximum transverse diameter. In case of ischemia, the lesions were noted according to the extent of the arterial territory infarcted. The statistical analysis consisted in calculating of the frequencies and averages of the studied variables. The qualitative and quantitative variables were expressed, respectively, in frequencies and average \pm standard deviation. The Chi2 test and Pearson correlation test were used to establish a relationship between two quantitative variables and the comparison between two groups. The threshold of significance was set up at $p<0.05$. The study had received the approval of the ethics committee of the hospital.

\section{Results}

In a sample of 1964 stroke patients, there were 163 severe strokes. The overall avaerage frequency of severe stroke was $8.3 \%(\mathrm{CI}=95 \%)$. Among all cases, severe ischemia accounted for $3.2 \%$ and severe hemorrhage stroke for $5.1 \%$. Of the 163 serious strokes, ischemic stroke accounted for $38.7 \%$ and hemorrhagic stroke for $61.3 \%$. The very serious strokes were observed in 98 cases and the gravicim one in 65 cases. The distribution of severe strokes per year is shown in Table 1 .

Table 1. Distribution of severe stroke by year.

\begin{tabular}{lllll}
\hline Years & $\begin{array}{l}\text { Stroke } \\
\text { type }\end{array}$ & Stroke & $\begin{array}{l}\text { Severe } \\
\text { stroke }\end{array}$ & Frequence (\%) \\
\hline \multirow{2}{*}{2015} & $\mathrm{IS}^{*}$ & 551 & 28 & $5.1\left(\mathrm{CI}^{\ddagger} 95 \%=4.2-5.9 \%\right)$ \\
& $\mathrm{HS}^{\dagger}$ & 345 & 67 & $19.4\left(\mathrm{CI}^{\ddagger} 95 \%=17.1-21.7 \%\right)$ \\
& Total 1 & 896 & 95 & $10.6\left(\mathrm{CI}^{\ddagger} 95 \%=9.6-11.6 \%\right)$ \\
\multirow{2}{*}{$201+$} & $\mathrm{IS}^{*}$ & 627 & 35 & $5.6\left(\mathrm{CI}^{\ddagger} 95 \%=4.7-6.5 \%\right)$ \\
& $\mathrm{HS}^{\dagger}$ & 441 & 33 & $7.5\left(\mathrm{CI}^{\ddagger} 95 \%=6.3-8.7 \%\right)$ \\
& Total 2 & 1068 & 68 & $6.4\left(\mathrm{CI}^{\ddagger} 95 \%=5.7-7.1 \%\right)$ \\
\hline
\end{tabular}

Legend: IS*: Ischemic stroke, $\mathrm{HS}^{\dagger}$ : Hemorrhagic stroke, $\mathrm{CI}^{\ddagger}$ : Confidence intervalle

The distribution of patients by age group according to stroke subtype is given Figure 1. 


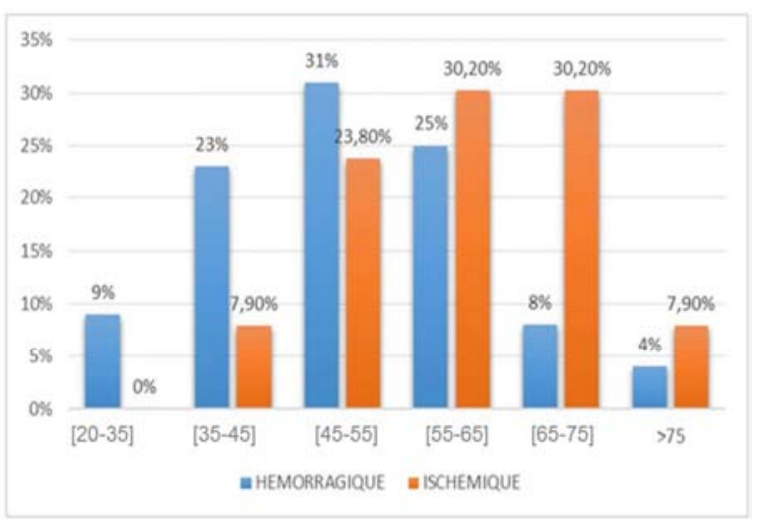

Figure 1. Distribution of patients by age range according to stroke subtype.

Regarding the antecedent, the duration of evolution of hypertension $(64.8 \%)$ was on average of $6.74 \pm 5.64$ years with extremes of 1 and 30 years. Among hypertensive patients, $59.5 \%(\mathrm{n}=97)$ were regularly followed up and $8 \%$ $(\mathrm{n}=13)$ were not. The seniority of the diabetes mellitus was on average of $6.69 \pm 6.53$ years with extremes of 0.25 and 20 years. The average year old of a pass stroke was $4.25 \pm 5.15$. Of the 26 patients with a previous history of stroke $(15.1 \%)$, 3 had hemorrhagic stroke (11\%) and $23(89 \%)$ had infarction. Sequels were found in 18 patients $(66.7 \%)$.

A statistical correlation was noted between the presence of diabetes and the type of stroke $(\mathrm{p}=0.003)$. There was a statistical correlation between stroke type and alcohol consumption $(\mathrm{p}=$ $0.02)$, obesity $(\mathrm{p}=0.003)$, HIV infection $(\mathrm{p}=0.004)$, tobacco $(\mathrm{p}=$ $0.004)$ and hypercholesterolemia $(\mathrm{p}=0.008)$.

Table 2. Distribution of patients according to severity parameters.

\begin{tabular}{lllll}
\hline & Average & SD & Minimum & Maximum \\
\hline NIHSS Scale & 22.8 & 8.9 & 13 & 37 \\
Glasgow Scale & 10.03 & 7.5 & 3 & 15 \\
DAP (mm hg) & 99.8 & 20.6 & 50 & 160 \\
SAP (mm hg) & 170.6 & 36 & 80 & 280 \\
Temperature $\left({ }^{\circ} \mathrm{C}\right)$ & 37 & 3 & 36 & 39 \\
\hline
\end{tabular}

Legend: SAP: systolic arterial pressure; DAP: diastolic arterial pressure; SD: standard deviation.
The mode of occurrence was sudden in $96 \%$ and successive on 24 - 48 hours in $4 \%$. The average admission time was 51.23 \pm 12.7 hours (range: 1 and 720 hours). The distribution of the signs of stroke severity is located in table 2 .

The location of stroke lesions is found in the table 3 and the complications in table 4.

Table 3. Localisation of intracerebral hematomas.

\begin{tabular}{lll}
\hline & Nomber & Percentage (\%) \\
\hline Diencephalic & 62 & 67.4 \\
Brainstem & 20 & 21.7 \\
Telencephalic & 7 & 7.6 \\
Cervelet & 3 & 3.3 \\
Total & 92 & 100 \\
\hline
\end{tabular}

Table 4. Hematomas complications.

\begin{tabular}{lll}
\hline & Nomber & Percentage (\%) \\
\hline Ventricular contamination & 38 & 50 \\
Axial engagement & 24 & 31.6 \\
Hydrocephalus and ventricular contamination & 14 & 18.4 \\
Total & 76 & 100 \\
\hline
\end{tabular}

The aetiology of severe stroke infarction were atherosclerosis of large arterials trunks in 51 cases $(81 \%)$, cardiac embol, 8 cases (12.7\%), and indetermined causes in 4 cases $(6.3 \%)$. Specific treatments for serious ischemic stroke were anti thrombotic by heparin and antiplatelet in $95.2 \%$. No one undergo thrombolysis, decompressive surgery or external ventricular derivation.

Between the $8^{\text {th }}$ and $15^{\text {th }}$ day after severe stroke, clinical stabilization was noted for $82 \%$ of cases and aggravation with death in $18 \%$. The clinical course was characterized by the occurrence of 53 early deaths (between the first and seventh day), related to a neurological aggravation or medical complications, bringing the hospital precoce mortality rate to $35.5 \%$. The haemorrhagic mortality was $69.8 \%(\mathrm{n}=37)$ and the ischemic mortality was $30.2 \%(\mathrm{n}=$ 16). The complications according to the subtype of stroke were shown in Figure 2.

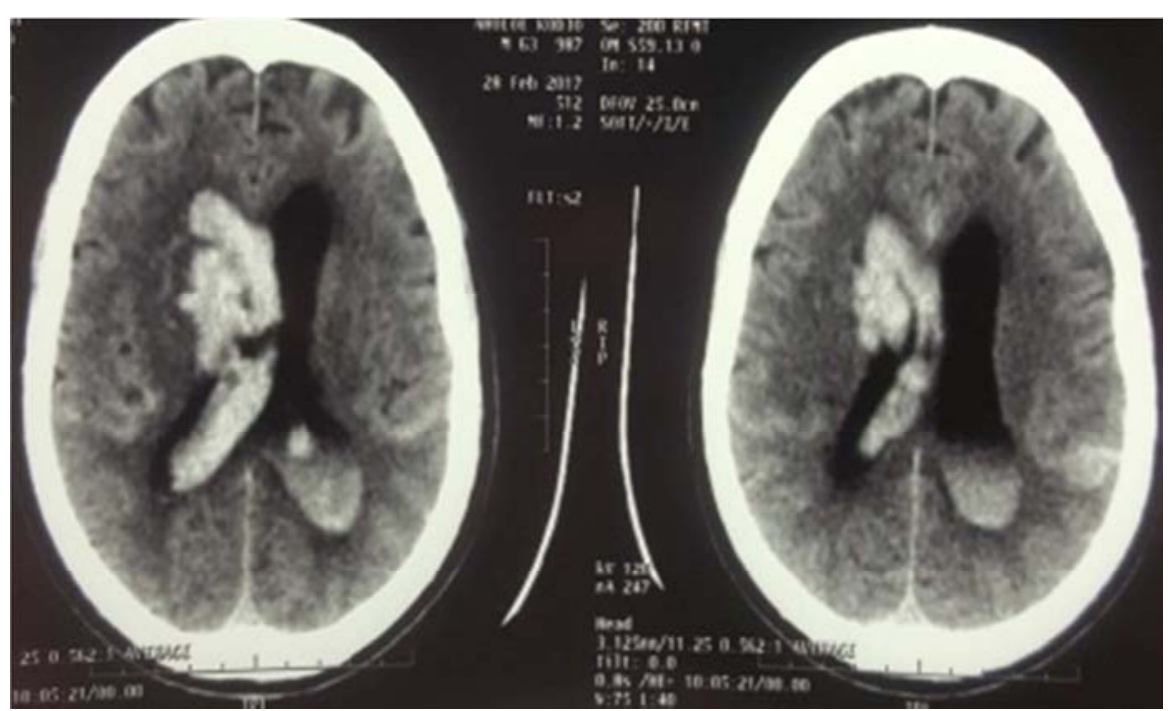




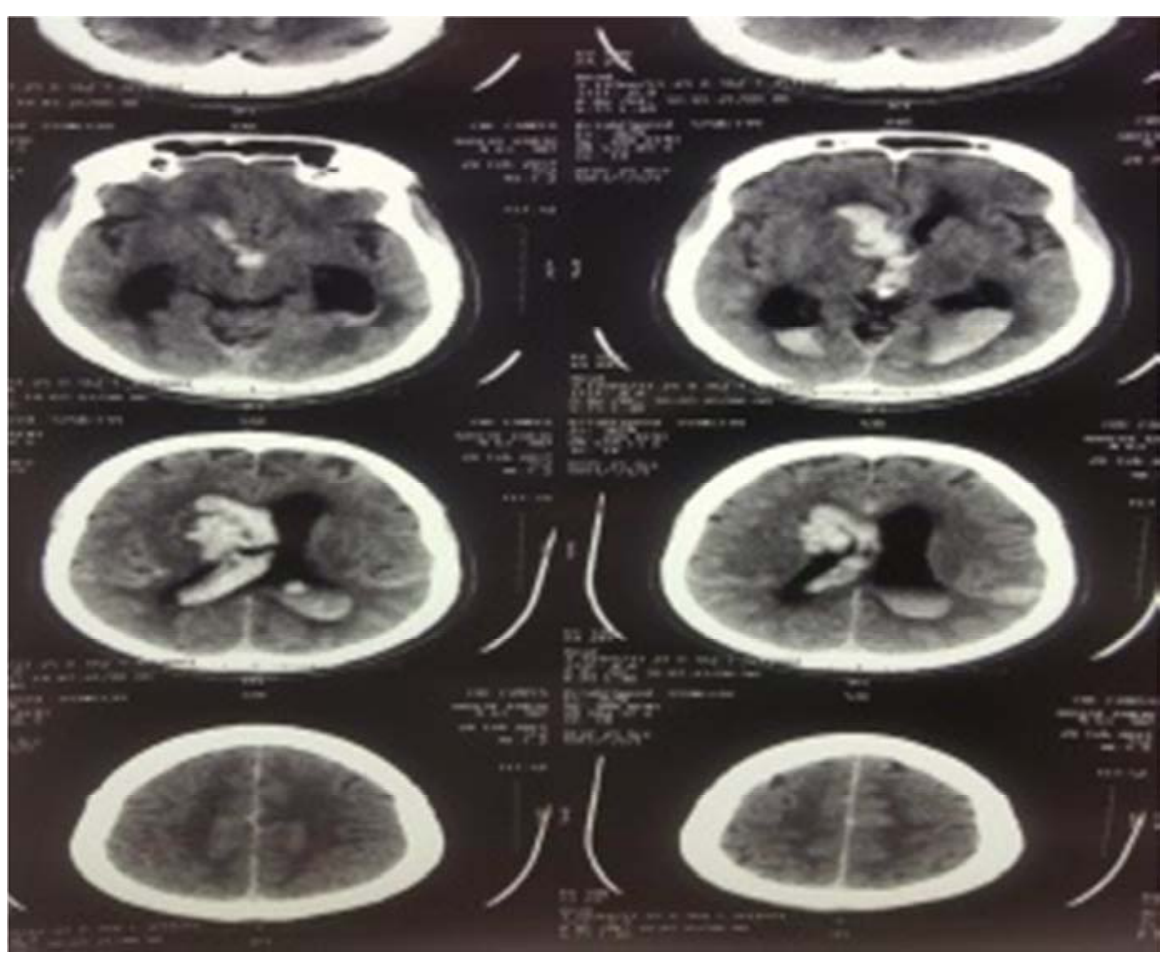

A
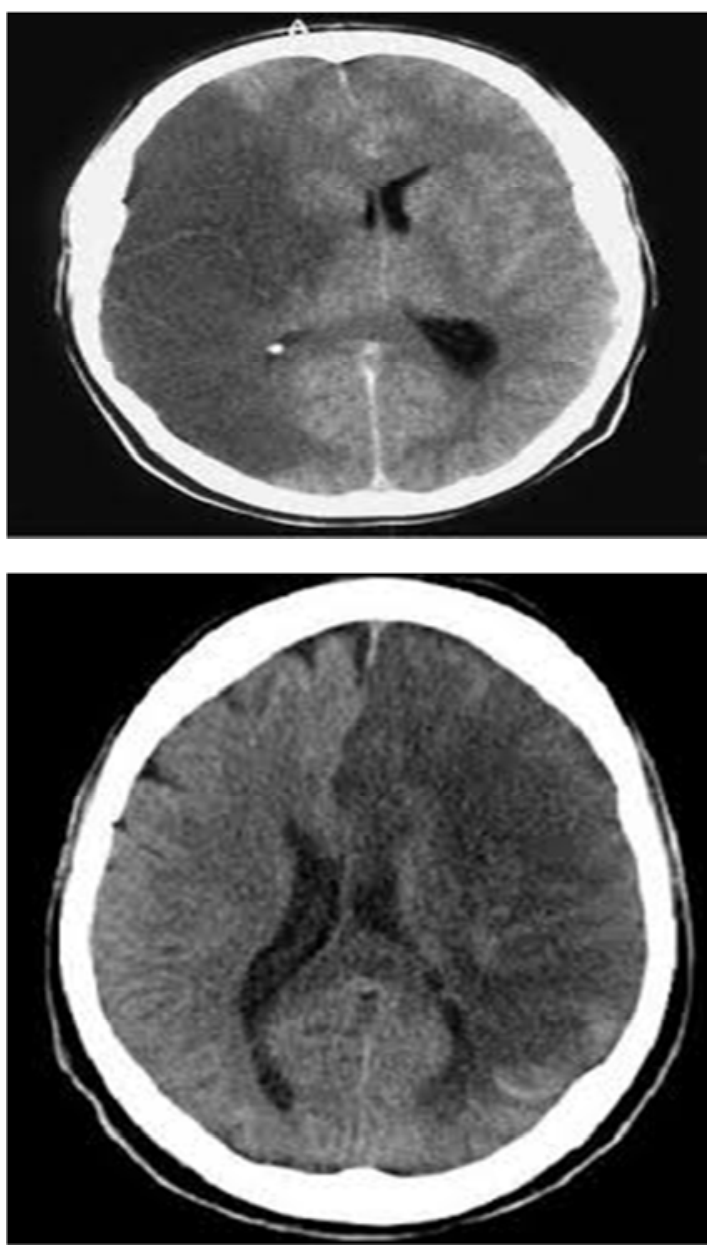

Figure 2. A: Spontaneaous hyperdensity in the right internal capsule with ventricle contamination and hydrocephalus; B: Right and left total hemispheric infarction, complications by hydrocephalus and engagement due to occlusion of middle cerebral artery. 
The overall mortality was $44.8 \%$. There was a statistical correlation between hospital mortality and hematoma volume $(\mathrm{p}=0.001)$, encephalic complications $(\mathrm{p}=0.003)$, high blood pressure $(\mathrm{p}=0.004)$, loss of consciousness at admission $(\mathrm{p}=$ $0.0001)$, and delayed to resuscitation management $(\mathrm{p}=$ 0.0003 ) in different subgroups of patients.

\section{Discussion}

\subsection{Analysis of the Methodology}

This primary study on severe stroke in the country with a methodology according to standards epidemiological recommendations, encountered the following constraints and difficulties. The lack of financial means of patients, thus reducing the practice of useful explorations, the insufficiency of the technical tools necessary for the diagnosis (brain MRI, cerebral CT angiography), and the treatment (rt-PA for thrombolysis, equipment of intubation and assisted ventilation, electric syringes, invasive monitoring). The use of CT scan instead of MRI played on the accuracy of the anatomical location of the lesion. The only study setting was the neurology department, which reduced the number of included patients. Despite all these insufficiencies, the validity of the results carried out by the study might be shared with the scientific community [12-14].

\subsection{Epidemiological Aspects}

The incidence of severe stroke was estimated at $8.3 \%$ for all strokes. It is lower than frequencies determined by other authors (11.2 to $27 \%$ ) [15-17]. The low frequency could be explained by the patient recruitment environment that only represented by the neurology department. The neurosurgical and resuscitation units were not included in the study, could probably underestimating the frequency of severe stroke. The multiple technical problems encountered in the medical imaging department (repeated failures of the brain scanner) as well as the absence of brain MRI for the diagnosis of the posterior fossa stroke have strongly contributed to underestimate the frequency of severe stroke. The lack of financial ressources with some patients could explain the non-achievement of brain imaging tests. The death of some serious stroke before their arrival at the hospital is also another argument. However, the frequency of haemorrhage and severe infarction observed in this study is in the same intervals as reported by previous authors in the literature [1820].

The average age of patients with severe stroke was 55.78 years; represent younging patients still in professional activities for the most part. The high representativeness of the over 45 ages group is explained by the increased of stroke rate occurring (doubled every decade) in this period [22]. Severe stroke is becoming more common in young people in Africa and could be explained by the lack of management of risk factors. The average age found in our study is lower than the result found previously $[5,6,21]$. This difference would result from the increase in prevalence and the difficulty of managing vascular risk factors in the elderly $[13,22]$. We did not find any predominance of sex in our study (sex ratio $\mathrm{H} /$ F: 1.01). The literature finds a predominance of the male sex $[6,20]$.

No statistical correlation could be established between the types of severe stroke and the socioeconomic status of patients due to their small numbers. The high representativeness of the professional active population $(71.8 \%)$ suggests that work-related stress or insignificant income, and the lifestyle changes by people in developing countries, could increase the prevalence of risk factors such as hypertension, diabetes mellitus, alcoholism, and smoking. A US study has reported that the risk of stroke will be doubled in low socioeconomic income countries [18]. However, the causal link would rather be the high prevalence of risk factors $[23,24]$. In addition, the high proportion of illiterate and low-educated patients in $41.4 \%$ and $32.5 \%$, respectively, could justify the difficulty of understanding and applying the management of major cardiovascular risk factors.

\subsection{Clinical Aspects}

High blood pressure is the main antecedent and risk factor $(64.8 \%)$. These findings related to the high rate of hypertension have been reported in the literature by other authors [22, 25, 26]. High blood pressure should be continually detected and well treated at an early stage to prevent its heavy complications. This could reduce the risk of severe stroke. There is a continuous relationship between the high level of blood pressure and the occuring of stroke, regardless of type and location. The frequency of hypertension is high in deep hemispheric and infratentorial haemorrhages [27, 28].

Conserning the time of admission, the average was $51.23 \pm$ 12.7 hours. Only $15 \%$ of them were hospitalized within 3 hours and $80.4 \%$ within 24 hours. This time of admission is longer than that reported by some authors who noted that 39.2 to $55 \%$ of patients had consulted within the first six hours $[17,21,29]$. In industrialized countries, $32 \%$ of stroke patients arrived in the emergency unit by 1.5 hours after the onset of illness, $46 \%$ within three hours and $61 \%$ within six hours $[13,20]$. There is a considerable delay in establishing the diagnosis and initiating adequate medical treatment to patient. This high delay in developing countries could be explained by the lack of insurance system, the inadequacy of the warning and medical evacuation systems, the first contact with traditional healers or inadequate health facilities, the unavailability of an emergency medical transport system and ignorance of the first signs of the stroke. These factors must be corrected in order to improve the vital and functional prognosis of patients with severe stroke.

Regarding the mode of occurrence, the brutal installation was the most predominant mode of occurence. The slow and progressive installation of the clinical condition (4\%), which has been observed, suggests that the presentation of certain 
serious infarctions is sometimes misleading, as in brainstem infarctions [30]. Therefore, any patient with or suspected stroke regardless of the initial signs severity should be referred to the neurovascular intensive unit.

With regard to reason and general condition at admission, motor deficit and impaired consciousness were the main reasons with a frequency of $76.1 \%$ and $62.6 \%$ respectively. Special emphasis should be placed on these two symptoms when raising the awareness of stroke among population. A very severe stroke had been found in $61 \%$ of patients. These results are greater than those reported previously who noted a predominance of patients with a very serious stroke (Glasgow score below 7 and NIHSS $>20$ ) [4, 6, 12]. These differences could be explained by the choice of the study framework and the inclusion criteria. Some authors believed that the Glasgow score for coma assessment after a severe stroke is a good predictor and a reliable tool for comatous stroke follow-up [28, 30]. In the same sense, it is accepted that this score is an important criteria for the prediction of stroke mortality. However, it remains very insufficient to predict disabilities. The initial evaluation of the severity of the stroke is primarily based on a clinical scale, the NIHSS score and prognostic factors, which are mainly studied in the severe stroke situation, including the Glasgow score scale [5, $6,16]$. The NIHSS score should therefore be an assessment tool for stroke patients and well used by all neurologists.

\subsection{Paraclinic Aspects}

The particularity of this study is the neuroradiological exploration of acute patients by the CT scan only, although the MRI is not yet available to the emergency department of the hospital. The review of the literature reveals that posterior fossa infarcts and the brainstem are well explored by MRI. $[29,31]$. The time to perform brain imaging was long, approximately 2 days. This had a considerable delay in establishing the diagnosis and initiate adequate treatment. The high delay could be explained by the critical state of the patients whose stabilization is a first priority than the realization of the CT scan, lack of financial resources, long admission period after onset, absence and unavailability of the CT scan in the neurology department and some technical problems encountered in the radiology service. The organization of a pathway for stroke management would reduce this delay $[6,17,21]$.

A preponderance of sus tentorial strokes (on average $80 \%$ ) was noted, regardless of the type of stroke, similar to previous results $[20,23]$. The involvement of the various structures of the posterior fossa was noted, particularly those of the brainstem, dominated by the protuberant localization in both types of stroke as reported by some authors $[32,33]$. As cerebral MRI could not be performed in emergency in our patients, the volume of ischemia was not been calculated, limiting the estimate of the risk of malignant edema, especially in cases of total or superficial sylvian or vertebral basilar arteries infarction if it was greater than $145 \mathrm{~cm}^{3}$ [34].

\subsection{Etiologic Features}

In this study, MRI and CT scan for cerebral palsy were performed in some patients with a delayed in order to confirm the diagnosis of basilar arterial infarct or to search for a vascular malformation or underlying tumor. We identified 9 cases of aneurysms and 5 cases of vascular malformations in cases of hematoma. High blood pressure, the main stroke risk factor $(83.5 \%)$, is also the main etiologic factor for hemorrhages in this study. This result is consistent with $65.2 \%$ observed by another authors [35]. The occlusion of large arterial trunks with atheroma plaques, strongly represented in this study (86.4\%) as an etiology of ischemic stroke, reflects the increasing incidence of cardiovascular risk factors (hypertension, diabetes mellitus, obesity, dyslipidemia) in population according to the changing of lifestyle.

\subsection{Therapeutic Aspects}

The management in a NVU with resuscitation, including mechanical ventilation and neurosedation in the acute phase of stroke, is recommended during severe stroke [17, 24, 33].

Neurosedation, monitoring and treatment of intracranial high pressure, pain, anxiety, agitation and stress and the decreased of sympathetic reaction was administered to $58.2 \%$ of our patients. This is far superior to some practices who sedated concomitantly with intubation, $16.2 \%$ and $24 \%$ of patients, respectively $[6,20,36]$ Delayed diagnosis, lack of MRI and non-availability of thrombolysis treatment justified the use of antithrombotic therapy alone (heparin and antiplatelet therapy), even when treatment with thrombolysis was indicated [37, 38].

The benefit of surgery in the indication of acute hydrocephalus with ventricular drainage is mainly related to the precocity of the action that the decision is taken and should not be delayed. [39]. However, the long admission time in the neurology department and the long time for brain imaging achievement, the lack of financial resources of some patients could not motivated the realization of this therapy which could possibly contribute to decrease the mortality[36]. However, it is necessary to put out the application of these methods and its effective realization in our countries in daily practice.

\subsection{Evolutive and Prognostic Aspects}

Overall mortality in our patients was $44.8 \%$. This result is lower than $75 \%$, that reported by authors in literature. All of our early deaths occurred during the first week of hospitalization, bringing early mortality rate to $35.5 \%$ versus $33 \%$ reported in previous studies [27]. This high mortality would probably be related to the long time of admission and hospitalization period in the neurology department, and the difficulties of management. Our patients could not benefit from intubation and mechanical ventilation, or even thrombolysis or external ventricular derivation. These early deaths could also be related to the size of the hematoma, the state of consciousness of the patient at admission, the 
encephalic complications, high blood pressure, occlusion of the basilar trunk with coma and respiratory distress $[5,32$, 40]. Thus, early management of swallowing disorders and other complications in the acute phase of severe stroke would be of considerable benefit for severe stroke patients.

\section{Conclusion}

The incidence of severe stroke and the high early mortality rate demonstrate that stroke remains a real public health problem low income resources countries. The therapeutic strategies currently used in the neurovascular intensive care units, indicate that there are great challenge of stroke management in general and particularly for severe stroke. National and global systemic efforts in the uniform organization of stroke pathway medical system are essential to improve these difficulties.

\section{Conflicts of Interest}

All the authors do not have any possible conflicts of interest

\section{References}

[1] Adams HP, del Zoppo G, Alberts MJ. Guidelines for the early management of adults with ischemic stroke. Stroke 2007; 38: $1655-71$.

[2] Lin DD, Gailloud P, Beauchamp NJ. Combined stent placement and thrombolysis in acute vertebrobasilar ischemic stroke. Am J Neuroradiol 2003; 24: 1827-33.

[3] Frankel MR, Morgenstern LB, Kwiatkowski T. Predicting prognosis after stroke: a placebo group analysis from the National Institute of Neurological Disorders and Stroke rt-PA Stroke Trial. Neurology 2000; 55: 952-9.

[4] Broderick JP, Adams HP, Barsan W. Guidelines for management of spontaneous intracerebral hemorrhage. Stroke 1999; 30: 905-15.

[5] Schwamm LH, Pancioli A, Acker JE, Goldstein LB, Zorowitz $\mathrm{RD}$, Shephard TJ, et al. Recommendations for the establishment of stroke systems of care: recommendations from the American Stroke Association's Task Force on the Development of Stroke Systems. Circulation 2005; 111: 1078-91.

[6] Manjila S, Masri T, Shams T, Chowdhry SA, Sila C, Selman WR. Evidence-based review of primary and secondary ischemic stroke prevention in adults: a neurosurgical perspective. Neurosurg Focus 2011; 30: 125-32.

[7] Brewer L, Mellon L, Hall P, Dolan E, Horgan F, Shelley E. Secondary prevention after ischaemic stroke: the ASPIRE-S study. BMC Neurology. 2015; 15: 216-21.

[8] Heuschmann PU, Kircher J, Nowe T, Dittrich R, Reiner Z, Cifkova $R$, et al. Control of risk factors after ischaemic stroke across Europe: data from the stroke-specific module of the EUROASPIRE III survey. European Journal of Preventive Cardiology. 2015; 22(10): 1354-62.
[9] Grigoryan M, Chaudhry SA, Hassan AE, Suri FK, Qureshi AI. Neurointerventional procedural volume per hospital in United States: implications for comprehensive stroke center designation. Stroke J Cereb Circ 2012; 43: 1309-14.

[10] Ding D. Endovascular mechanical thrombectomy for acute ischemic stroke: a new standard of care. J Stroke 2015; 17 : 123-9.

[11] Badhiwala JH, Nassiri F, Alhazzani W, Selim MH, Farrokhyar F, Spears J, et al. Endovascular thrombectomy for acute ischemic stroke: a meta-analysis. JAMA 2015; 314: 1832-43.

[12] Weshler LR. Imaging evaluation of acute ischemic stroke. Stroke 2011; 42: 12-7.

[13] Lacy CR, Suh DC, Bueno M, Kostis JB. Delay in presentation and evaluation of acute stroke: Stroke Time Registry for Outcomes Knowledge and Epidemiology (STROKE). Stroke 2001; 32: 63-9.

[14] Ois A, Cuadrado-Godia E, Jimenez-Conde J. Early arterial study in the prediction of mortality after acute ischemic stroke. Stroke 2007; 38: 2085-9.

[15] Edlow JA, Newman-Toker DE, Savitz SI. Diagnosis and initial management of cerebellar infarction. Lancet Neurol 2008; 7(10):951- 64 .

[16] Dufour M, Bouafe A, Bruder N. Diagnosis in general hospital and immediate care of patients suffering from severe subarachnoid haemorrhage. Ann Fr. Anesth Reanim 2005; 25: 715-20.

[17] Jones F, Riasi A, Norris M. Self-management after stroke: time for some more questions. Disabil Rehabil. 2013; 35(3): 257-64.

[18] Jones F, Mandy A, Partridge C. Changing self-efficacy in individuals following a first time stroke: preliminary study of a novel self-management intervention. Clin Rehabil. 2009; 23(6): 522-33.

[19] Howard G, Cushman M, Kissela BM. Traditional risk factors as the underlying cause of racial disparities in stroke: lessons from the half full (empty?) glass. Stroke 2011; 42(12): 3369 75 .

[20] Rees L, Marshall S, Hartridge C, Mackie D, Weiser M. Cognitive interventions post acquired brain injury. Brain Inj. 2007; 21(2): 161-200.

[21] Sene Diouf F, Mapoure NY, Ndiaye M, Ndiaye MM, Sow A, Ndiaye IP. Survival of comatose stroke patients in Dakar (Senegal). Rev Neurol 2008; 68: 606-10.

[22] Goldstein LB, Adams R, Alberts MJ. Primary prevention of ischemic stroke: Stroke 2006; 37: 1583-92.

[23] Grotto I, Huerta M, Sharabi Y. Hypertension and socioeconomic status. Curr Opin Cardiol 2008; 23(4): 335-9.

[24] Freedman KS, Nelson NM, Feldman LL. Smoking initiation among young adults in the United States and Canada, 19982010: A systematic review. Prev Chron Dis 2012; 9: 1103-7.

[25] Mahoungou-Guimbi KC, Ellenga-Mbolla BF, DambaBanzouzi BY. Hemorrhagic strokes in intensive care unit. Rev. Afr. Anesth. Méd. Urg, 2012; 17(3): 51-5.

[26] Holloway RG, Benesch CG, Burgin WS. Prognosis and decision making in severe stroke. JAMA 2005; 294: 725-33. 
[27] Crozier S, Santoli F, Outin H, Morini B, Gravio F, Tremoni A, et al. Grave strokes: intensive care unit admission criteria, decision of limitation and stop of treatment and prognostic. Rev Neurol 2011; 167: 468-73.

[28] Chobanian AV, Bakris GL, Black HR, Cushman WC, Donald CG, Green A, et al. Seventh report of the joint national committee on prevention, detection, evaluation and treatment of high blood pressure. Hypertension, 2003; 42: 1206-52.

[29] Calvet D, Bracard S, Mas J-L. Arterial and veinous cerebral ischemic treatment. Experts formalized recommendations for stroke management by urgentist. Revue Neurol, 2012; 168: $512-21$.

[30] Weir CJ, Bradford AP, Lees KR. The prognostic value of the components of the Glasgow coma scale following acute stroke. QJM 2003; 96: 67-74.

[31] Boulogne S, Roggerone S, Deiana G, Lemaire G, Cristoli F, Regis A, et al. Bilateral paramedian bulbar infarction of progressive evolution: A study of cases with MRI. Rev Neurol 2014; 170: 277-9.

[32] Diallo M, Guindo M, Mariko O. Contribution of the CT scan in the diagnostics of rare cerenral hemorrhagic localisation at Gabriel Toure University Hospital of Bamako (Mali). J Afr Imag Méd 2014; 6(1): 72-8.

[33] Erro ME, Gallego J, Herrera M, Bermejo B. Isolated pontine infarcts: Etiopathogenic mechanism. Eur J Neurol 2005; 12: 984-8.
[34] Oppenheim C, Samson Y, Manai R. Prediction of malignant middle cerebral artery infarction by diffusion weighted imaging. Stroke 2000; 31: 2175-81.

[35] Diagana M, Ould ASB, N'diaye M, Seydou B, Sy L, Sarr B, et al. Impact of cares chain in acute phase of stroke to improve functional outcome in Nouakchott. AJNS 2008; 27: 39-46.

[36] Jacobi J, Fraser GL, Coursin DB, Riker RR. Clinical practice guidelines for the sustained use of sedatives and analgesics in the critically ill adult. Crit Care Med 2002; 30: 119-41.

[37] Montavont A, Nighoghossian N, Derex L. Intravenous rtPA in vertebrobasilar acute infarcts. Neurology 2004; 62: 1854-6.

[38] Schonewille WJ, Wijman CA, Michel P. Treatment and outcomes of acute basilar artery occlusion in the Basilar Artery International Cooperation Study (BASICS): A prospective registry study. Lancet Neurol 2009; 8: 724-30.

[39] Vahedi K, Hofmeijer J, Juettler E. Early decompressive surgery in malignant infarction of the middle cerebral artery: A pooled analysis of three randomized controlled trials. Lancet Neurol 2007; 6: 215-22.

[40] Jung S, Mono ML, Fisher U. Three-month and log-term outcomes and their predictors $\mathrm{I}$ in acute basilar artery occlusion treated with intra-arterial thrombolysis. Stroke 2011; 42: 1946-51. 